\title{
UN PASO MAS HACIA LA DELIMITACION DE LA INVIOLABILIDAD DE DOMICILIO EN NUESTRO DERECHO
}

por

\section{Tomás Quintana López}

La Sentencia de la Sala Segunda del Tribunal Constitucional de 17 de octubre de 1985 (Boletín Oficial del Estado de 8 de noviembre), dictada en el recurso. de amparo número 124 del mismo año, nuevamente pone de relieve la tensión que puede surgir en un Derecho entre el principio de autotutela administrativa y alguno de los derechos fundamentales constitucionalmente garantizados (1).

1. El caso que traemos a estas páginas no es nuevo, lo que nos obliga a recordar, siquiera sea brevemente, algunas sentencias que precedieron a la que últimamente dictó el supremo intérprete de la Constitución.

Con anterioridad a 1978, nuestros Tribunales, que nosotros conozcamos, se pronunciaron en una ocasión, concretamente, la Audien-

(1) Tambien se puso de manifiesto esta tension, en este caso entre la tutela efectiva de Jueces y Tribunales que garantiza el articulo 24 de la Constitucion y la efectividad de los actos administrativos, en la Sentencia del Tribunal Supremo de 17 de julio de 1982. comentada por Miguel SÁNCHEZ MORON, REDA, núm. 35, 1982, páginas 669 y ss. 
cia Territorial de Burgos, mediante Sentencia de 23 de octubre de 1975 (2); en ella, la Sala entiende que la Administración no precisa la autorización judicial para ejecutar sus actos, pese a que la ejecución exija la entrada en el domicilio del obligado por el acto administrativo previo.

Ya en 1982, el Tribunal Supremo vuelve a resolver en idéntico sentido, Sentencia de 7 de diciembre (3), manteniendo en esta ocasión que la Administración no precisa autorización judicial para entrar en el domicilio del sujeto obligado para ejecutar, de conformidad con la resolución administrativa previa, la destrucción del inmueble, sustrato físico del domicilio.

Con posterioridad, y precisamente en el mismo asunto, el Tribunal Constitucional se pronuncia por Sentencia de 17 de febrero de 1984 (4), contradiciendo los fundamentos de la Sentencia del Tribunal Supremo, otorgando amparo al recurrente y sentando una clara doctrina que obliga a la Administración a obtener una autorización judicial previa cuando la ejecución forzosa del acto administrativo precise la entrada en el domicilio del sujeto que no cumplió voluntariamente el contenido del acto (5).

II. La Sentencia que ahora nos ocupa, partiendo de unos presupuestos distintos a los que concurrían en los casos antes mencionados, resuelve en sentido negativo una petición de amparo por presunta vulneración del derecho a la inviolabilidad de domicilio.

Algunos datos recogidos de los antecedentes de la Sentencia nos van a ser útiles para la comprensión de ciertos fundamentos de la misma. La Sociedad Anónima Derivados de Hojalata solicitó del Juzgado de Primera Instancia declaración de estado de suspensión de pagos (el día 30 de enero de 1984), y durante la sustanciación del expediente, hasta que se dicta el auto de aprobación del convenio (7 de mayo de 1985), se realizan una urie de actuaciones de trascendencia para el caso. La Administración tributaria levantó el día 17 de mayo de 1984 acta de defraudación contra la entidad;

(2) Comentada por Fracisco SoSA WAGNER, REDA, num. 14, 1977, págs. 481 y ss.

(3) Comentada por Bartoloméu COLOM PASTOR, REDA, núms. 40 y 41,1984 , páginas 249 y ss.

(4) Comentada por Tomás Quintana Lopez, Revista de Estudios DE LA VIDA LOCAL, núm. 224,1984 , págs. 543 y ss.

(5) En la doctrina se han mantenido tesis discrepantes a su contenido. Vid. Fernado LOPEZ RAMON:. «Inviolabilidad del domicilio y autotutela administrativa en la jurisprudencia del Tribunal Constitucional», REVISTA DE ESTUDiOS DE LA ADMINISTRACIÓN LOCAL Y AUTONOMICA, núm. 225, 1985, págs. 31 y ss.I Tomás FONT I LLOVET: La ejecución de las sentencias contencioso-administrativas. Aspectos constitucionales, 1985, pags. 129 y ss. 
transcurrido el período voluntario de pago sin haberse efectuado, Hacienda inicia el correspondiente procedimiento de apremio, solicitando, como un trámite más del mismo, la autorización judicial para entrar en el domicilio de la entidad mercantil deudora, resolviendo el Juzgado de Distrito número 1 mediante auto autorizatorio; contra esta resolución la entidad interesada recurre en distintas instancias, argumentando que no procedía otorgar la autorización de entrada en el domicilio mientras estuviera tramitándose el expediente de suspensión de pago, obteniendo siempre contestación negativa, la última de ellas, a través de auto de 18 de enero de 1985 , del Juez de Primera Instancia que venía conociendo de la suspensión de pagos.

La solicitud de amparo fue realizada mediante escrito de demanda de 18 de febrero de 1985; obviamente, no lo fundamenta en la presunta vulneración del derecho a la inviolabilidad del domicilio por carecer la Administración del correspondiente pronunciamiento judicial, pues lo hubo, sino en la supuesta inconstitucionalidad de los artículos 130 de la Ley General Tributaria y 103 y 115 del Reglamento General de Recaudación, inconstitucionalidad sobrevenida por ser anteriores a la Constitución y oponerse a los artículo 18, 2; 117,3 y 4 , de la Constitución, ya que, según se desprende de los antecedentes de la Sentencia, estos preceptos posibilitan una resolución del Juez carente de contenido racional y sin motivación, un mero acto formal, puramente procedimental, pues el órgano jurisdiccional desconoce la razón por la que autoriza la entrada en el domicilio.

Dados los términos en que se plantea el amparo no resulta excesivamente dificultoso intuir las razones en favor de la resolución negativa del Tribunal Constitucional, pues la presunta inconstitucionalidad denunciada de los preceptos citados de nuestro ordenamiento tributario tiene como único apoyo la consideración de que su tenor conduce al Juez a permitir, de forma automática, la entrada de los agentes ejecutivos en el domicilio del providenciado de apremio para poder ejecutar la deuda líquida impagada. Efectivamente, la Sala Segunda al resolver el asunto no hace otra cosa que desmentir la interpretación que el demandante hace de tales preceptos y respaldar, con la suya propia, la actuación del Juez que autorizó la entrada; en consecuencia, permite una lectura constitucional de los articulos afectados por el recurso al afirmar: 
«Resulta, pues, de la sucinta exposición anterior, de un lado, que todo el iter del procedimiento de apremio viene siendo conocido por el titular del domicilio $y$, por supuesto, sabedor también de la legal y reglamentaria posibilidad de que el agente cjecutivo penetre en el mismo, para práctica del embargo, provisto - eso sí- del indispensable mandamiento judicial; y, de otro lado, que esa resolución judicial de algún modo cabria reputar que se inserta en el procedimiento administrativo de ejecución forzosa. sin que se hallen ausentes determinadas posibilidades de formación de juicio por parde del titular del órgano jurisdiccional, juicio conducente al otorgamiento o denegación de lo instado, por plurales causas o motivos, que aqui no vamos a enumerar exhaustivamente, pero que tanto pueden ser discordantes en orden a la debida individualización del sujeto pasivo tributario, como a irregularidades trascendentes observadas en las actuaciones que se reflejan en los documentos que la Administración tributaria ha de presentar ante el Juzgado, con su solicitud de mandamiento de entrada en un domicilio.

Quiérese decir que, no obstante permitir la dicción legal y reglamentaria, entender que la autoridad judicial actúa de un modo que podria calificarse como automático, ello no puede ser asi...".

Descalificada la pretendida interpretación de los artículos 150 y 103 y 115 de la Ley General Tributaria y del Reglamento General de Recaudación, respectivamente, el Tribunal Constitucional mantiene que no se menoscabe el derecho a la inviolabilidad de domicilio cuando la entrada en éste por los agentes administrativos, aun sin consentimiento de su titular, se produce previa autorización judicial, siempre que ésta no sea expresión de una actividad automática o cuasiautomática.

Con esta declaración se forma el núcleo fundamental de la Sentencia, de la que se sirve el Tribunal para rechazar la pretensión de amparo. No'obstante, realiza además unas importantes precisiones que nos permiten concretar el alcance de la garantía constitucional de la inviolabilidad de domicilio.

III. En el recurso que resuelve el Tribunal Constitucional mediante la Sentencia que comentamos, se plantea la extensión a las personas jurídicas del derecho fundamental que contiene el artículo 18,2 , de la Constitución. Quizá porque nunca se había suscitado la posible aplicación de este derecho cuando quien lo invoca es una persona jurídica, el Alto Tribunal, en anteriores resoluciones (6),

(6) Sentencia de 17 de febrero de 1984 y Auto de abril de 1985, aunque especificamente referido este al derecho a la intimidad que preve el articulo 18,1 , de la Constitucion. 
establece una estrecha vinculación entre la intimidad domiciliaria y la persona física, como titular de la garantía constitucional; sin embargo, a través de esta Sentencia se rechaza la exclusiva aplicación del artículo 18, 2, de la Constitución para la protección del domicilio de las personas físicas, desechándose, por si las anteriores resoluciones hubieran dado lugar a una errónea conclusión, la tesis de que las personas jurídicas no pueden ser titulares del derecho a la inviolabilidad de domicilio, de acuerdo con la regulación constitucional. La doctrina que sienta el Tribunal Constitucional en esta Sentencia no ofrece equívocos:

"Ausente de nuestro ordenamiento constitucional un precepto similar al que integra el arlículo 19, 3, de la Ley Fundamental de Bonn, según el cual los derechos fundamentales rigen también para las personas juridicas nacionales, en la medida en que, por su naturaleza, les resulten aplicables, lo que ha permitido que la jurisprudencia aplicativa de tal norma entienda que el derecho a la inviolabilidad del domicilio conviene también a las entidades mercantiles, parece claro que nuestro Texto Constitucional, al establecer el derecho a la inviolabilidad del domicilio, no lo circunscribe a las personas fisicas, siendo, pues, extensivo o predicable igualmente en cuanto a las personas juridicas, del mismo modo que este Tribunal ha tenido ya ocasión de pronunciarse respecto de otros derechos fundamentales, como pueden ser los fijados en el artículo 24 de la misma Constitución Española, sobre prestación de tutela judicial efectiva, tanto a personas físicas como a juridicas.

Este es también el criterio aceptado por la doctrina. generalizada en otros paises, como pueden ser, dentro de Europa, en Alemania, Italia y Austria, donde se sigue un criterio que puede reputarse extensivo, llegado el momento de resolver esta misma cuestión, pudiendo entenderse que este derecho a la inviolabilidad del domicilio tiene también justificación en el supuesto de personas juridicas, y posee una naturaleza que en modo alguno repugna la posibilidad de aplicación a estas últimas, las que - suele ponerse de relievetambién pueden perder su carácter por el hecho de que el titular sea uno u otro; derecho fundamental que cumple su sentido y su fin también en el caso de que se incluyan en el circulo de los titulares de este derecho fundamental a personas juridicas u otras colectividades".

IV. La posición que el Tribunal Constitucional mantiene en cuanto a la garantía de inviolabilidad del domicilio de las personas jurídicas es absolutamente clara (7): el artículo 18, 2, de la

(7) En España ha mantenido el derecho a la inviolabilidad del domicilio de las 
Constitución debe proporcionar una cobertura común a todas las personas. Ahora bien, con esta afirmación no se resuelve la viva problemática que plantea el alcance de la protección o garantía; sin duda, el Tribunal Constitucional ha estado atento a esta observación, para argumentar como sigue:

«En suma, la libertad del domicilio (8) se califica como reflejo directo de la protección acordada en el ordenamiento a la persona, pero no necesariamente a la persona física, desde el momento en que la persona juridica venga a colocarse en el lugar del sujeto privado comprendido dentro del área de la tutela constitucional, y todas las hipótesis en que la instrumentación del derecho a la libertad no aparezcan o sean incompatibles con la naturaleza y la especialidad de fines del ente colectivo».

No resulta fácil fijar los límites en los que se han de desenvolver el artículo 18,2, de la Constitución cuando se trata de entidades mercantiles las destinatarias de la garantía constitucional. El problema, tratándose de personas físicas, encuentra una, relativamente, sencilla solución, debido a la coincidencia del domicilio con la vivienda, sea ésta permanente o temporal; espacio que se identifica con el marco donde la persona proyecta gran parte de su vida privada, que es, en definitiva, lo que el derecho a la inviolabilidad de domicilio trata de poner a salvo de la injerencia ajena, aunque ésta provenga de la Administración pública. Pero en relación con las personas jurídicas, iqué aspectos de éstas, o más concretamente de las entidades mercantiles, encuentran acomodo en la garantía constitucional? El Tribunal Constitucional hace una importante precisión al exigir que «la persona jurídica venga a colocarse en el lugar del sujeto privado comprendido dentro del área de la tutela constitucional». Sin duda, lo que se pretende con esta afirmación es desechar la posibilidad de que todo lo que tenga una dependencia física con la entidad mercantil quede al amparo de la tutela constitucional, que se prevé en el artículo 18,2, con lo que parece prescribir el peligro, ya anunciado en la doctrina (9), al que son más proclives las

personas juridicas, entre otros, Ricardo GARCiA MACHO: "La inviolabilidad de domicilio", $R E D A$, núm. 32, 1982, pág. 857.

(8) Entendemos que la referencia a la libertad de domicilio lo es a la inviolabilidad de domicilio, ya que sobre este derecho resuelve en esta Sentencia el Tribunal Constitucional, no tratándose más que de un error.

(9) Vid. LOPEZ RAMON: «Inviolabilidad del domicilio...», pág. 37. 
entidades mercantiles, de utilizar la inviolabilidad de domicilio para fines espúreos, como es la defensa ilegítima de sus bienes, obstaculizando indebidamente la legitima, mientras no cambie nuestro régimen administrativo, actuación de la Administración en ejercicio de su potestad de autotutela.

En consecuencia, no consideramos tarea inútil dedicar alguna atención a delimitar el círculo de intereses de las entidades mercantiles que encuentran protećción en el derecho a la inviolabilidad de domicilio. De acuerdo con este objetivo, lo primero que creemos deben ser tenidas en cuenta son las posibilidades que ofrece el concepto mercantil de domicilio social, para ver si puede ser considerado como objeto protegible por el derecho fundamental que nos ocupa; el artículo 5 de la Ley de Sociedades Anónimas de 17 de julio de 1951, ejemplo paradigmático del asociacionismo mercantil, nos ofrece suficientes razones para no tomar en consideración el domicilio social como círculo de intereses inviolables, sino con autorización judicial; el precepto citado nos remite a una serie de criterios (el lugar en que se halle establecida su representación legal, donde radique alguna de sus explotaciones o ejerza la entidad actividades propias de su objeto) ajenos, o cuando menos exorbitantes, a la esencia de la protección domiciliaria que depara nuestra Constitución.

Según entendemos, la inviolabilidad de domicilio ha de servir para amparar el lugar donde las personas jurídicas, y la entidad mercantil entre ellas, reflejan su actividad; a partir de este principio se hace preciso confrontar, caso por caso, si las exigencias de la autotutela administrativa han de rendirse ante el reducto de aspectos tutelados por este derecho, para decidirse en sentido negativo cuando lo que se pretende salvaguardar son otros derechos, cuya legitimidad encuentra protección a través de otros cauces previstos en el ordenamiento, pero no mediante el fundamental derecho a la inviolabilidad de domicilio. Es preciso atajar la utilización abusiva de esta garantía, que representa una posible tentación, para detener la actuación ejecutiva de la Administración al hacer efectivos sus créditos, lo que equivaldría, de admitirse, a menoscabar el principio de autotutela de la Administración. Además, en. supuestos en que ésta no acompañe su actuación ejecutiva de los trámites que legalmente vienen exigidos, el particular, sin tener que recurrir a otros remedios previstos para garantizar otros derechos, puede utilizar 
vías distintas, también sumarias y de efectos paralizantes, como son los interdictos, admitidos en nuestro Derecho frente a la Administración cuando ésta no actúa de acuerdo con el procedimiento legalmente establecido (10).

(10) Vid. Eduardo Garcia de EnTERria y Tomás-Ramón Fernández Rodriguez: Curso de Derecho Administrativo, I, 4. ${ }^{\text {a }}$ ed., 1983, pág. 746. 